\title{
FPGA Based Implementation of Symmetrical Reduced Switch Multilevel Inverter
}

\author{
K. Venkataramanan ${ }^{1}$, B. Shanthi ${ }^{2}$, T. S. Sivakumaran ${ }^{3}$ \\ ${ }^{1}$ Department of Electrical and Engineering, Arunai Engineering College, India \\ ${ }^{2}$ Centralised Instrumentation and Service Laboratory, Annamalai University, India \\ ${ }^{3}$ Department of Electrical and Engineering, Arunai College of Engineering, India
}

\begin{tabular}{l}
\hline \hline Article Info \\
\hline Article history: \\
Received Jan 1, 2017 \\
Revised Feb 2, 2017 \\
Accepted Feb 7, 2017 \\
\hline Keywords: \\
CFD \\
FPGA \\
MLI \\
PWM \\
THD
\end{tabular}

\begin{abstract}
Multilevel inverter has become more popular and attractive for drive applications. Among the various modulation techniques, Carrier based techniques has been commonly used because of their simplicity and flexibility. This paper presents the comparisons of bipolar multicarrier pulse width modulation for the new symmetrical multilevel inverter. The performance parameters of new multilevel inverter were analyzed through various switching strategies. The detailed study has been carried out by MATLAB/SIMULINK. The real time implementation was carried out using FPGA. The results of both simulation and experimentation were compared.
\end{abstract}

Copyright $(0) 2017$ Institute of Advanced Engineering and Science. All rights reserved.

\section{Corresponding Author:}

K.Venkataramanan, Department of Electrical and Engineering, Arunai Engineering College, India.

Email: raceramana@gmail.com

\section{INTRODUCTION}

A multilevel inverter is a power electronic system that synthesizes a desired output voltage from several levels of DC voltage as inputs. Multilevel Inverter (MLI) is not only achieves high power ratings but also enables the use of renewable energy sources, due to this, industries are mostly preferred this converters. The conventional inverters provide only two level voltage but we get several level from MLI which results in high power quality, lesser harmonic components, improved electromagnetic compatibility and lower switching losses. The main objective of multilevel topologies is the increase of power, the fall in voltage stress on the switches and the generation of excellence output voltages and sinusoidal currents. Different topologies are proposed namely DCMLI, FCMLI and CHBMLI. These topologies are differing by the operating mechanism.

Many modulations techniques have been developed like fundamental switching method, pulse width modulation, selective harmonic elimination and space vector modulation etc. Out of these techniques, PWM techniques have been widely used because of their ease and litheness. Carrara et al discussed control freedom degrees combination and their analysis for PWM methods. Mohan et al discussed the single triangle PWM method and its variants are effective for controlling the inverters. Agelidis and Calais proposed carrier based multilevel PWM method which effectively control the diode clamped inverter. Martina Calais et al analyse the multicarrier schemes by applied in cascaded multilevel inverter. Aziz described the digital simulation study for modular structured multilevel inverter. Krein et al introduced modified carrier approach and it can be minimizing harmonics. Jana et al presented switching pattern for cascaded MLI based on space vector modulation technique. Mekhilef et al discussed the symmetrical digital pulse width modulation technique. Dahidah and Agelidis suggested that the selective harmonic elimination pulse width modulation is suitable 
for high power applications. Haiwen et al compared the fundamental switching method with pulse width modulation method by applying in cascaded multilevel inverter. Roozbeh Naderi and Abdolreza Rahmati developed phase shifted carrier PWM technique for cascaded inverters. Krishna described the conventional multilevel inverter to produce small voltage steps and series capacitor also used for voltage balance. Najafi et al proposed the reversing voltage topology for multilevel inverter. Babaei proposed cascaded multilevel inverter topologies with less power semiconductor devices. Ersoy Besery et al developed new symmetrical multilevel inverter with reduced switches. Whenever we are providing equal DC voltage sources as input then this type of inverter is mentioned as symmetrical multilevel inverter whereas unequal sources means asymmetrical multilevel inverter.

In this paper a new type of symmetrical multilevel inverter has been analyzed based on performance parameters through various PWM techniques and the simulation results were validated with the help of prototype model.

\section{NEW SYMMETRICAL MULTILEVEL INVERTER}

More number of switches required for traditional multilevel inverters, due to this circuit cost, installation area and switching losses becomes high and control circuit also complicated. To overcome this problem a new topology introduced in Figure 1.This topology consists of 3 auxiliary switches, 4 main switches, 3 diodes and three DC sources to form seven level. This new topology achieves reduction in the number of main power switches by $42 \%$. The next higher level can be obtained by adding a single switch, a diode and a DC source.

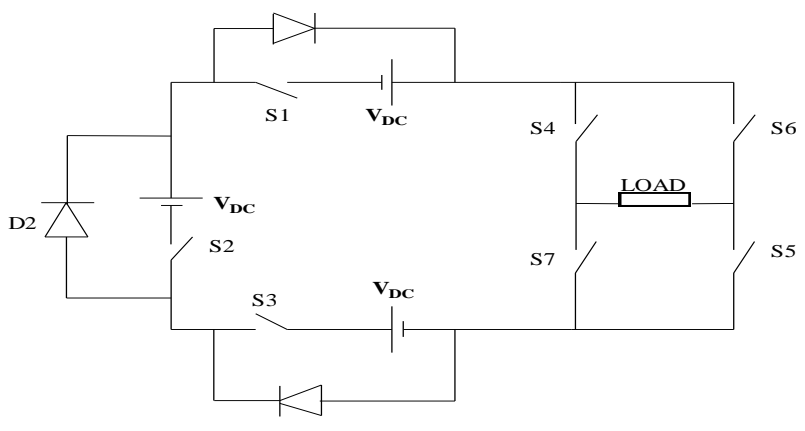

Figure 1. Symmetrical multilevel inverter

In order to obtain $3 \mathrm{~V}_{\mathrm{DC}}$ at the output, the switches $\mathrm{S} 1, \mathrm{~S} 2, \mathrm{~S} 3, \mathrm{~S} 4$ and $\mathrm{S} 5$ were $\mathrm{ON}$. The load is connected between $\mathrm{S} 4$ and S5. In this mode, all the three sources were connected in series which produces $3 \mathrm{~V}_{\mathrm{DC}}$ at the output. When S2, S3, S4 and S5 were ON and diode D1 conducts, only two sources were in series and generate $2 \mathrm{~V}_{\mathrm{DC}}$. To get $\mathrm{V}_{\mathrm{DC}}$ at the output, switch $\mathrm{S} 3, \mathrm{~S} 4$ and S5 is ON and diode D2 and D1 conducts.

The output voltage levels at the negative half cycle were achieved by connecting the load between S6 and S7 instead of S4 and S5.

\section{MODULATION STRATEGY}

Bipolar multicarrier based PWM strategies were used to switch the power devices to produce several levels at the output voltage. The PWM based strategies are most popular because of carrier, which controls inverter output voltage thus obtained by adjusting the conducting periods of power semiconductor switches. Carrier based strategies classified as single carrier and multicarrier strategies. Multicarrier PWM strategies such as, Phase disposition PWM, Alternate phase opposition disposition PWM and Carrier overlapping PWM were implement in this paper. Carrier based method operate based on the comparison of modulating signal with carrier signals where carrier signal can be triangular, sawtooth and any other shape based on control freedom degree including amplitude, frequency and offsets between carriers. For getting ' $\mathrm{m}$ ' levels, m-1 carriers are needed, for bipolar PWM Strategies. The carriers consist of same frequency $\mathrm{f}_{\mathrm{c}}$ and same peak to peak amplitude $A_{c}$. The modulating signal has amplitude $A_{m}$ and frequency $f_{m}$ and is placed at the middle of the carrier set. The frequency ratio $\mathrm{m}_{\mathrm{f}}$ is defined. In this paper, the modulating frequency $\mathrm{mf}$ is taken as 20 , modulating index ma varied from 0.7 to 1.0 . 
$\mathrm{m}_{\mathrm{f}}=\mathrm{f}_{\mathrm{c}} / \mathrm{f}_{\mathrm{m}}$

The amplitude modulation index $m_{a}$ is defined as $\mathrm{m}_{\mathrm{a}=} \mathrm{A}_{\mathrm{r}} / \mathrm{A}_{\mathrm{c}}$

\subsection{Phase Disposition Strategy}

In this strategy six triangular carrier with the identical frequency $f_{c}$ and peak-to-peak amplitude $A_{c}$ which are disposed so that the bands they occupy are contiguous. The carrier set is placed above and below the zero reference. The carrier arrangement for seven level inverter using PDPWM is shown in Figure 2. for $\mathrm{m}_{\mathrm{a}}=0.8$ and $\mathrm{m}_{\mathrm{f}=} 20$.

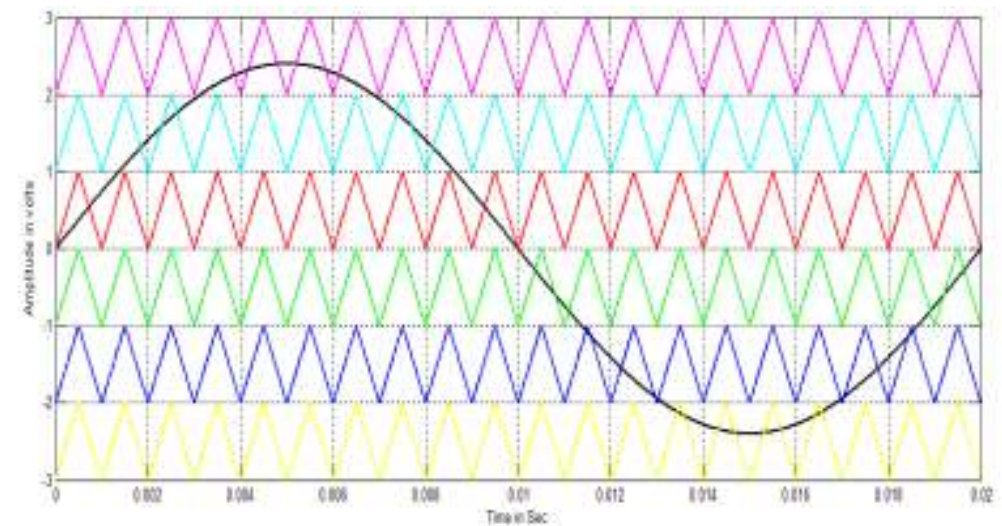

Figure 2. Multicarrier Arrangement for PDPWM Strategy

\subsection{Alternate Phase Opposition Disposition Strategy}

The six carriers are phase displaced from each other by 180 degrees alternately with identical frequency and peak to peak amplitude. Figure 3 Shows multicarrier arrangement for APOD method for $\mathrm{m}_{\mathrm{a}}=0.8$ and $\mathrm{m}_{\mathrm{f}=} 20$.

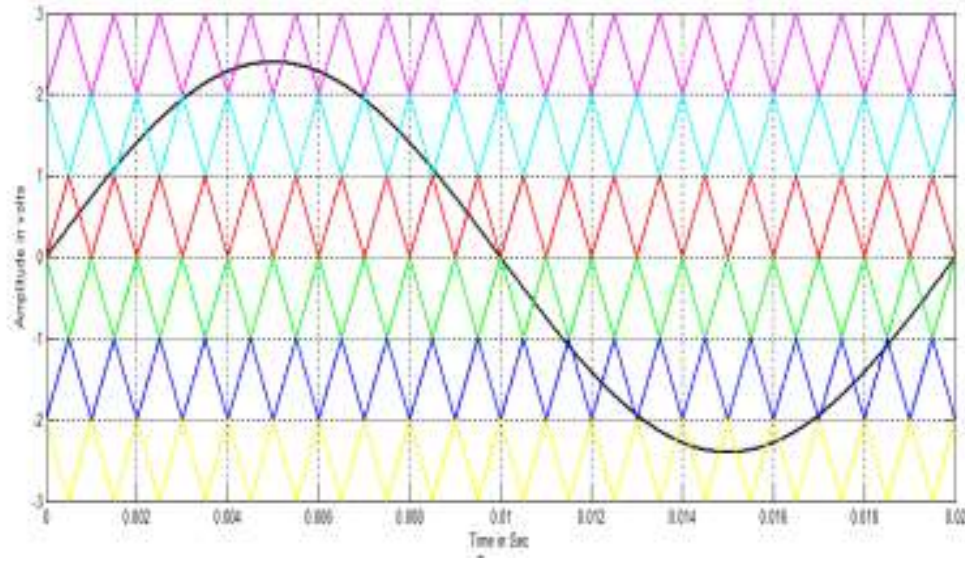

Figure 3. Multicarrier Arrangement for APODPWM Strategy

\subsection{Carrier Overlapping Strategy}

The COPWM strategy utilizes the control freedom degree of erect offsets among carriers. The principle of COPWM is to use a number of overlapping carriers with modulating signal. The six carriers disposed such that the bands they inhabit overlap each other. The overlapping magnitude among all carriers is $\mathrm{A}_{\mathrm{c}} / 2$ in this work. Figure 4 shows the multicarrier arrangement for COPWM Strategy for $\mathrm{m} 0.8$ and $\mathrm{m}_{\mathrm{f}=} 20$. 


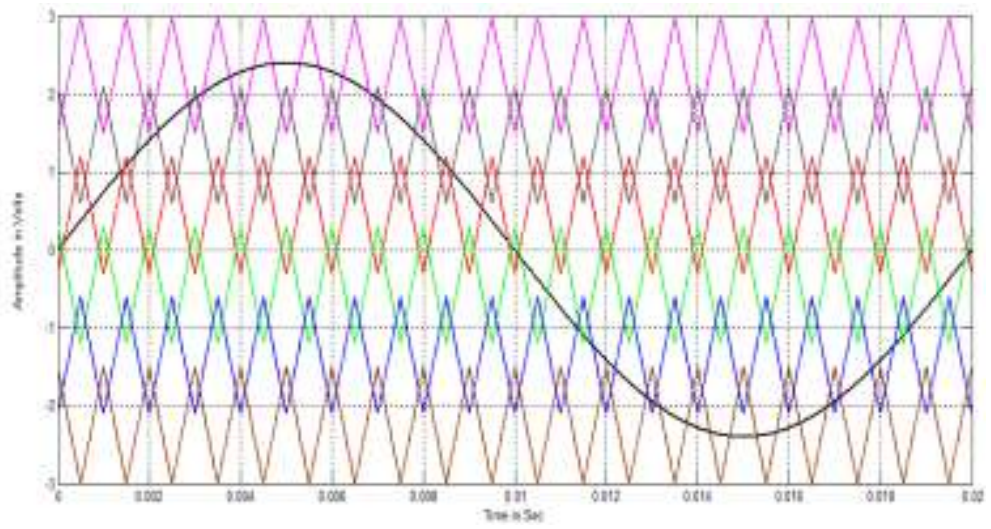

Figure 4. Multicarrier arrangement for COPWM strategy

\section{SIMULATION RESULTS}

The above symmetrical multilevel inverter is modeled in SIMULINK using power system block set. The gating signals are obtained by various PWM Strategy. Simulations are carried out for different modulation indices ranging from 0.7 to 1 . The performance parameters like THD, $\mathrm{V}_{\text {RMs. }}$. Figures 5-10 display the simulated output voltage and their FFT plot with above strategies but for only one sample value of $\mathrm{ma}=0.8$. Figure $10 \& 11$ explicites the graphical comparsion of all strategies.Figure 5 shows the seven level output voltage generated by PDPWM strategy and its FFT plot is shown in Figure 6. From Figure 6, it is observed that the PDPWM strategy produces significant $6^{\text {th }}, 8^{\text {th }}, 14^{\text {th }}$ and $20^{\text {th }}$ harmonic energy. Figure 7 shows the output voltage generated by APODPWM strategy and its FFT plot is shown in Figure 8. From Figure 8 it is observed that the APODPWM strategy produces significant $11^{\text {th }}, 13^{\text {th }}, 15^{\text {th }}, 17^{\text {th }}$ and $19^{\text {th }}$ harmonic energy. Figure 9 shows the seven level output voltage generated by COPWM strategy and its FFT plot is shown in Figure 10.From Figure 10 it is observed that the COPWM strategy produces significant $5^{\text {th }}, 11^{\text {th }}, 13^{\text {th }}, 15^{\text {th }}$ $17^{\text {th }}$ and $19^{\text {th }}$ harmonic energy.Table 2 indicates that $\%$ distortion factor is low compared with other strategies. The subsequent parameter values are taken for simulation: Vdc $=100 \mathrm{~V}$, Resistive load $-10 \mathrm{ohms}$, $\mathrm{f}_{\mathrm{m}=} 50 \mathrm{~Hz}, \mathrm{f}_{\mathrm{c}}=1000 \mathrm{~Hz}$.

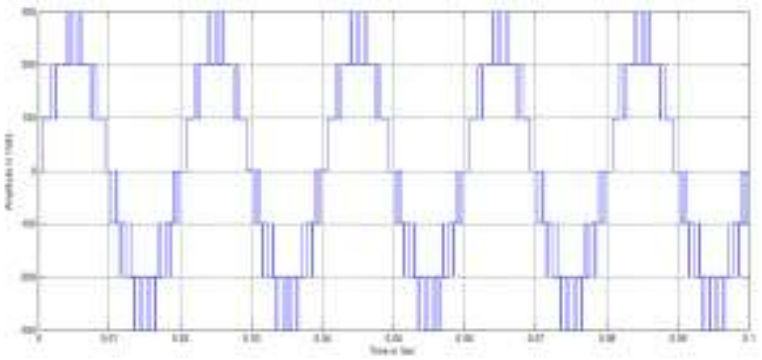

Figure 5. Simulated Output Voltage Generated by PDPWM

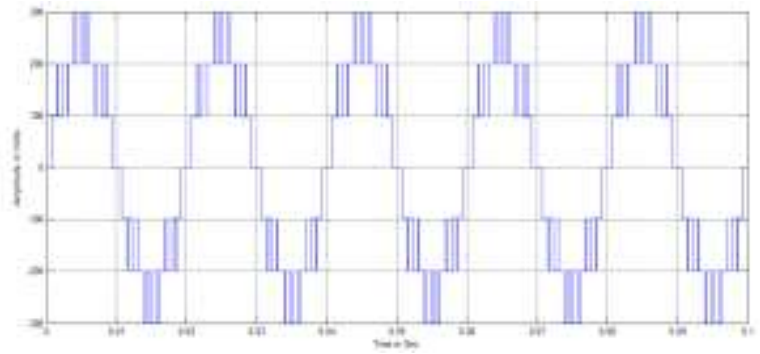

Figure 7. simulated output voltage generated by APODPWM

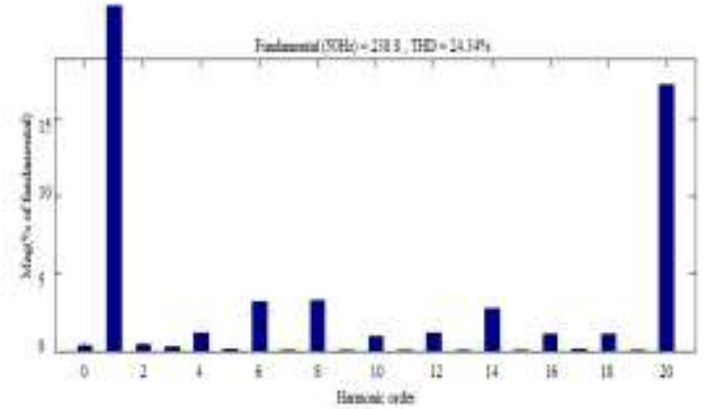

Figure 6. FFT Spectrum for PDPWM

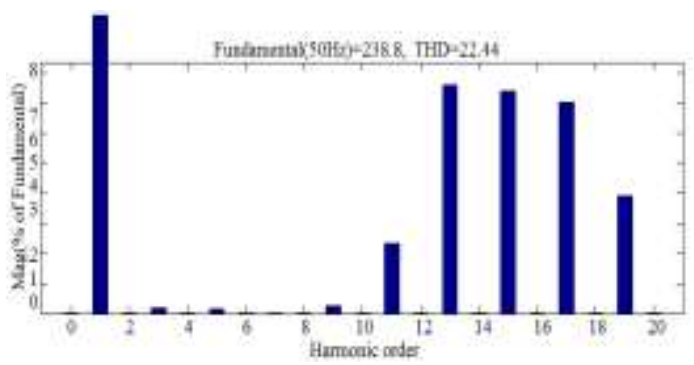

Figure 8. FFT spectrum for APODPWM

FPGA Based Implementation of Symmetrical Reduced Switch Multilevel Inverter (K.Venkataramanan) 


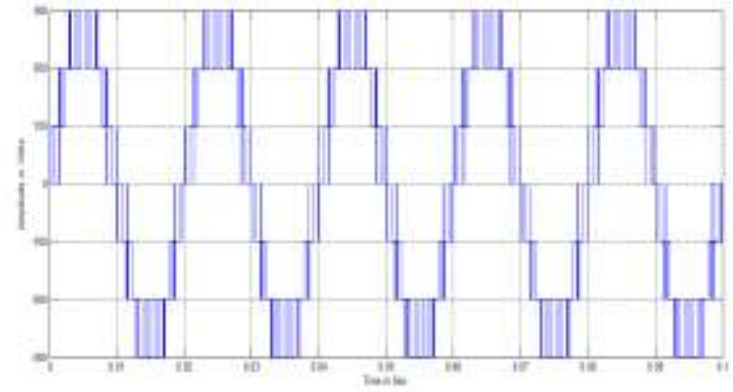

Figure 9. Simulated output voltage generated by COPWM

Table 1. \% THD for Different Modulation Indices

\begin{tabular}{cccc}
\hline $\mathrm{m}_{\mathrm{a}}$ & PD & APOD & CO \\
\hline 1.0 & 17.92 & 18.50 & 17.54 \\
0.95 & 20.39 & 21.23 & 19.86 \\
0.9 & 22.63 & 22.63 & 22.15 \\
0.85 & 23.79 & 22.56 & 24.31 \\
0.8 & 24.34 & 22.44 & 25.46 \\
0.75 & 24.13 & 22.62 & 25.26 \\
0.7 & 24.95 & 22.56 & 26.84 \\
\hline
\end{tabular}

Table 3. $\mathrm{V}_{\mathrm{RMS}}$ for Different Modulation Indices

\begin{tabular}{cccc}
\hline $\mathrm{m}_{\mathrm{a}}$ & PD & APOD & CO \\
\hline 1.0 & 211.8 & 211.8 & 221.6 \\
0.95 & 201.1 & 201.1 & 213.9 \\
0.9 & 190.2 & 190.3 & 205.9 \\
0.85 & 179.8 & 179.6 & 196.4 \\
0.8 & 168.9 & 168.8 & 185.7 \\
0.75 & 158.3 & 158.2 & 175.9 \\
0.7 & 147.4 & 147.4 & 168.8 \\
\hline
\end{tabular}

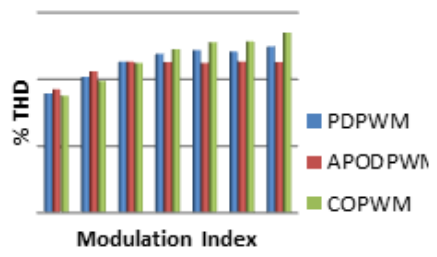

Figure 11. \% THD comparison of various modulation indices

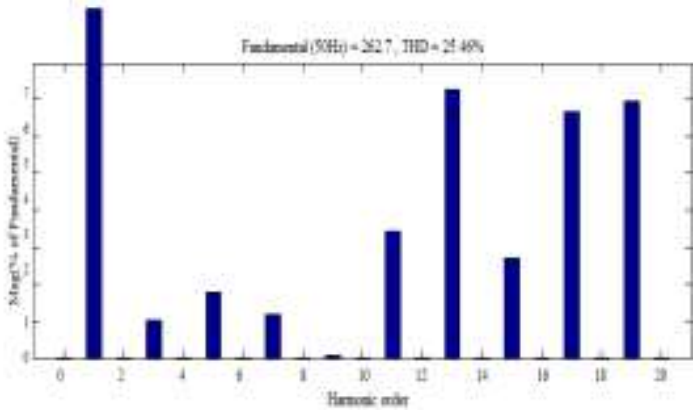

Figure 10. FFT spectrum for COPWM

Table 2. \% Distortion Factor for Different Modulation Indices

\begin{tabular}{cccc}
\hline $\mathrm{m}_{\mathrm{a}}$ & $\mathrm{PD}$ & APOD & $\mathrm{CO}$ \\
\hline 1 & 0.629 & 0.081 & 0.417 \\
0.95 & 0.5256 & 0.0672 & 0.3546 \\
0.9 & 0.4089 & 0.0742 & 0.2826 \\
0.85 & 0.2424 & 0.0777 & 0.136 \\
0.8 & 0.1754 & 0.0681 & 0.1491 \\
0.75 & 0.2253 & 0.0826 & 0.2846 \\
0.7 & 0.1462 & 0.0655 & 0.4525 \\
\hline
\end{tabular}

Table 4. Crest Factor for different modulation indices

\begin{tabular}{cccc}
\hline $\mathrm{m}_{\mathrm{a}}$ & PD & APOD & CO \\
\hline 1 & 1.414 & 1.414 & 1.418 \\
0.95 & 1.414 & 1.414 & 1.417 \\
0.9 & 1.414 & 1.414 & 1.415 \\
0.85 & 1.414 & 1.414 & 1.418 \\
0.8 & 1.414 & 1.414 & 1.427 \\
0.75 & 1.508 & 1.414 & 1.424 \\
0.7 & 1.414 & 1.414 & 1.392 \\
\hline
\end{tabular}

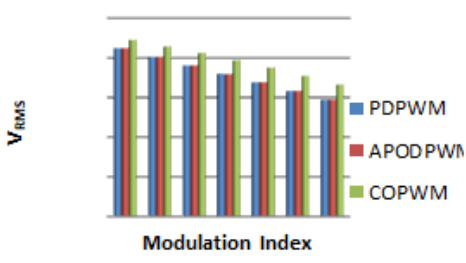

Figure 12. VRMS Comparison of Various Modulation Indices

\section{HARDWARE RESULTS}

This section presents the experimental work using Xilinx Spartan-3E XC3S100E FPGA system for symmetrical seven level inverter. Real time realization of these strategies using Spartan -3 requires less time. The experimental studies are carried out to appraise the performance of the inverter. To verify the performance of the inverter design on Hardware, the VHDL code (Bit file) is downloaded into the desired FPGA device (Spartan 3 family XC3S100). The real time setup is shown in Figure 14. The results are taken from Digital Storage Oscilloscope (DSO) and analysed through power quality analyser. After suitably the scaling down the simulation values, due to laboratory constraints input voltage set as $45 \mathrm{~V}$, each DC source carries $15 \mathrm{~V}$ and peak to peak output voltage experimentally is $90 \mathrm{~V}$. 


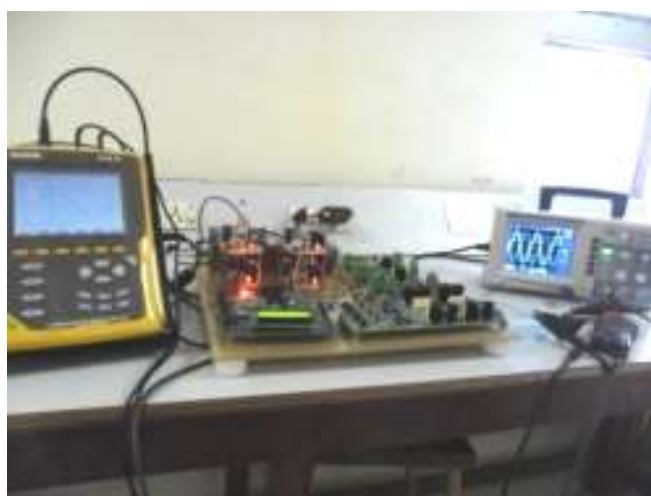

Figure 14. Hardware Setup of Symmetrical Multilevel Inverter

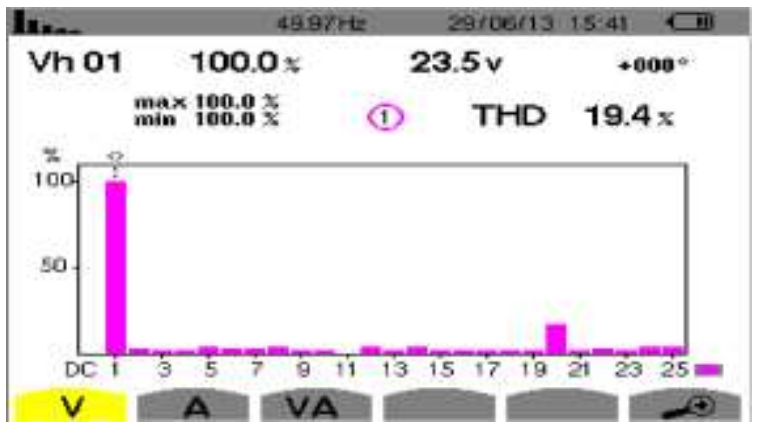

Figure 16. FFT spectrum for PDPWM

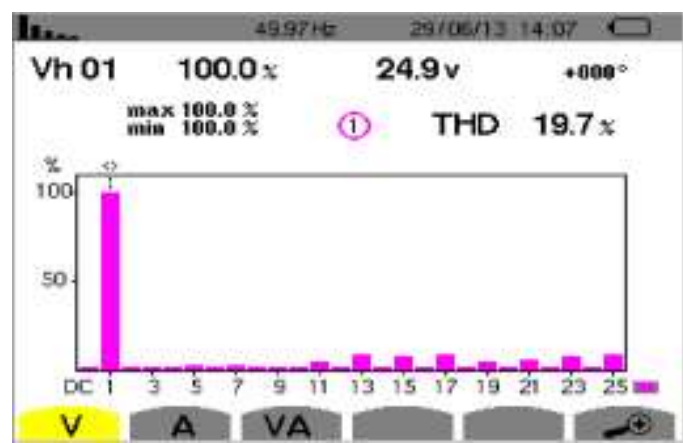

Figure 18. FFT spectrum for APODPWM

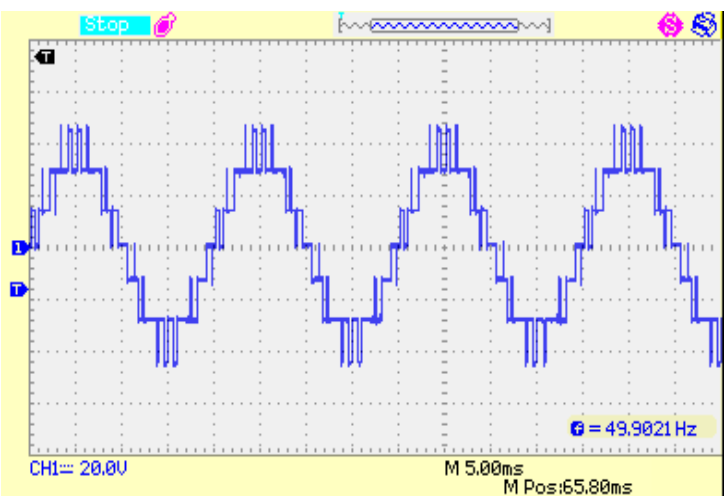

Figure 15 Hardware Output voltage of generated by PDPWM

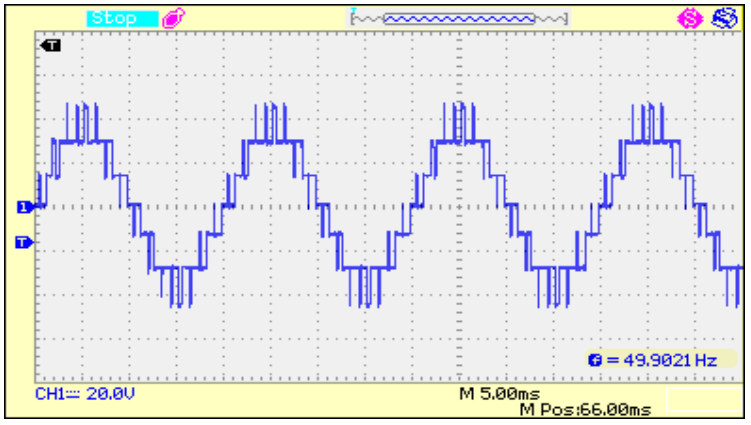

Figure 17. Hardware output voltage generated by APODPWM

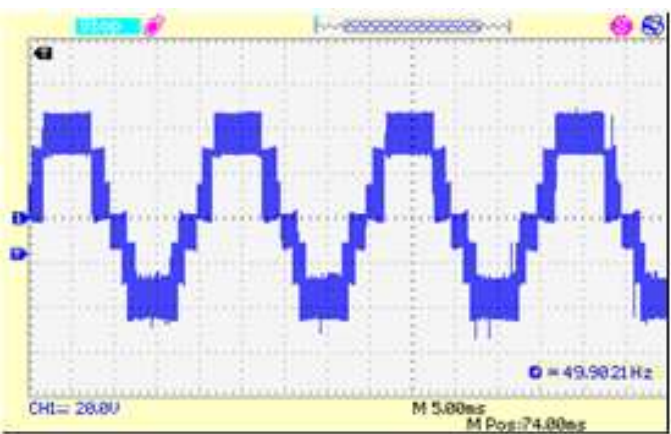

Figure 19. Hardware output voltage generated by COPWM

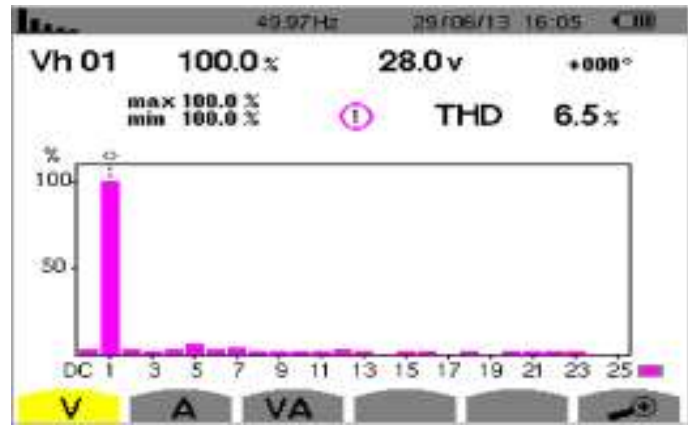

Figure 20. FFT spectrum for COPWM 
Table 5. \% THD for different modulation indices

\begin{tabular}{cccc}
\hline $\mathrm{m}_{\mathrm{a}}$ & PD & APOD & CO \\
\hline 1.0 & 14.7 & 15.5 & 6.0 \\
0.95 & 17.1 & 15.8 & 6.0 \\
0.9 & 19.1 & 18.6 & 6.1 \\
0.85 & 20.1 & 19.7 & 6.2 \\
0.8 & 19.4 & 19.7 & 6.5 \\
0.75 & 19.5 & 21.3 & 6.6 \\
0.7 & 19.1 & 21.0 & 6.8 \\
\hline
\end{tabular}

Table 7. $\mathrm{V}_{\mathrm{RMS}}$ for different modulation indices

\begin{tabular}{cccc}
\hline $\mathrm{m}_{\mathrm{a}}$ & $\mathrm{PD}$ & APOD & $\mathrm{CO}$ \\
\hline 1.0 & 31.8 & 31.7 & 33.5 \\
0.95 & 30.3 & 30.2 & 32.3 \\
0.9 & 28.6 & 28.6 & 30.7 \\
0.85 & 25.5 & 27.0 & 29.6 \\
0.8 & 23.5 & 24.9 & 28.0 \\
0.75 & 22.4 & 23.8 & 26.7 \\
0.7 & 22.1 & 22.4 & 25.0 \\
\hline
\end{tabular}

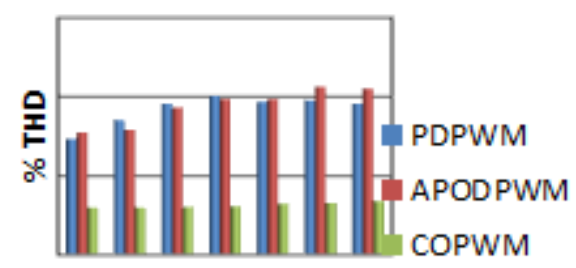

Modulation Index

Figure 21. \% THD comparison of various modulation indices
Table 6. \% Distortion Factor for different modulation

\begin{tabular}{cccc}
\multicolumn{4}{c}{ indices } \\
\hline $\mathrm{m}_{\mathrm{a}}$ & $\mathrm{PD}$ & APOD & CO \\
\hline 1 & 14.6 & 15.4 & 6.5 \\
0.95 & 17.1 & 17.9 & 6.7 \\
0.9 & 18.7 & 19.4 & 6.3 \\
0.85 & 19.9 & 19.9 & 6.6 \\
0.8 & 19.4 & 19.7 & 6.4 \\
0.75 & 19.8 & 21.4 & 7.2 \\
0.7 & 20 & 18.1 & 6.9 \\
\hline
\end{tabular}

Table 8. Crest Factor for different modulation

\begin{tabular}{cccc}
\multicolumn{5}{c}{ indices } \\
\hline $\mathrm{m}_{\mathrm{a}}$ & $\mathrm{PD}$ & APOD & CO \\
\hline 1 & 1.41 & 1.4 & 1.31 \\
0.95 & 1.48 & 1.49 & 1.36 \\
0.9 & 1.56 & 1.56 & 1.4 \\
0.85 & 1.64 & 1.64 & 1.45 \\
0.8 & 1.75 & 1.74 & 1.52 \\
0.75 & 1.86 & 1.86 & 1.58 \\
0.7 & 1.94 & 1.78 & 1.65 \\
\hline
\end{tabular}

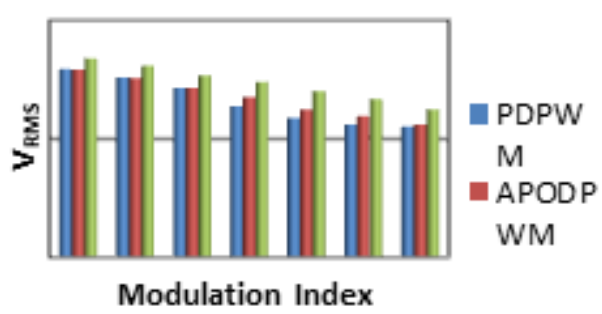

Figure 22. $\mathrm{V}_{\mathrm{RMS}}$ comparison of various modulation indices

\section{CONCLUSION}

In this paper, the various modulation strategies for reduced switch seven level Symmetrical Inverter have been discussed. The various performance parameters like \% THD , $\mathrm{V}_{\mathrm{RMS}}$, Distortion Factor and Crest Factor have been analysed and evaluated. It is observed that the Carrier Overlapping PWM provides least \% THD and Distortion factor for all $\mathrm{m}_{\mathrm{a}}$ and provides maximum RMS voltages when compared to other two strategies. At the same time APOD strategy provides nominal crest factor. The simulation results were closely matched with experimental results.

\section{REFERENCES}

[1] Agelidis V.G, Calais, M, "Application Specific Harmonic Performance Evaluation of Multicarrier PWM Techniques”, IEEE PESC, pp.172-178, 1998.

[2] Aziz J.A, Salam Z, "A new pulse width modulation (PWM) scheme for modular structured multilevel voltage source inverter”, Int.Journal of Electronics, vol.91,No.4,pp211-226, 2004.

[3] Babaei E, "A cascade multilevel converter topology with reduced number of switches", IEEE Trans. Power Electron.,vol.23, no.6, pp.2657-2664, 2008.

[4] Carrara.G, Gardella.S, Marchesoni.M, Salutari.R, Sciutto.G, "A new multilevel PWM method: a theoretical analysis", IEEE Trans.Power Electronics, vol.7, pp. 497-505, 1992.

[5] Dahidah M.S.A, Agelidis V.G, "Selective harmonic elimination PWM control for cascaded multilevel voltage source converters: A generalized formula”, IEEE Trans. Power Electron,vol.23,no.4, pp.1620-1630, 2008.

[6] Ersoy Besery,Birol Arifoglu,Sabri Camur,Esra Kandemir Beser, "Design and Application of a Single Phase Multilevel Inverter Suitable for using as a Voltage Harmonic Source", Journal of Power Electronics, vol 10, No.2,pp 138-145, 2010. 
[7] Haiwen, L, Tolbert, L.M, Ozpineci, B, Zhong, D, "Comparison of fundamental frequency and PWM methods applied on a hybrid cascaded Multilevel inverter", 34th IEEE Conference on Industrial electronics. Proc.pp. 32333237, 2008.

[8] Jana K.C, Biswas S.K, Thakura P, "A Simple and Generalized Space Vector PWM Control of Cascaded H-Bridge Multilevel Inverters”, IEEE International Conference on Industrial Technology.Proc,.pp1281-1286, 2006.

[9] Krein P.T, Nee B.M, Wells R, "Harmonic elimination switching through modulation", IEEE Workshop on Computers in Power Electronics. Proc.pp.123-126, 2004.

[10] Krishna S, "Harmonic Elimination by Selection of Switching Angle and DC Voltages in Cascaded Multilevel Inverters",15th National power system conference (NPSC). Proc. pp.119-124, 2008.

[11] Martina Calais, Lawrence J.Borle, Vassilios G. Agelidis., "Analysis of multicarrier PWM methods for a single phase five level inverter”, IEEE Conf. Rec.: 0-7803-7067-8/01, pp.1351-1356, 2001.

[12] Mekhilef S, Omar A.M, Rahim N.A, "Modelling of three-phase uniform symmetrical sampling digital PWM for power converter", IEEE Trans. Ind. Electron.,vol. 54, no. 1, pp.427-432, 2007.

[13] Mohan.N, Undeland T.M and Robbins W.P, Power Electronics: Converters,Applications, and Design, 2nd ed. New York: John Wiley \& Sons, 1995.

[14] Najafi,E.;Yatim,A.;Samosir,A.S, “A new topology -Reversing Voltage (RV)-for multi level inverters”, IEEE 2nd International Power and Energy Conference. Proc. pp.604 - 608, 2008.

[15] Roozbeh Naderi., Abdolreza Rahmati, "Phase -shifted carrier PWM technique for general cascaded inverters", IEEE Trans.on Power Electronics,vol.,No.13,pp19-14, 2008.

\section{BIOGRAPHIES OF AUTHORS}
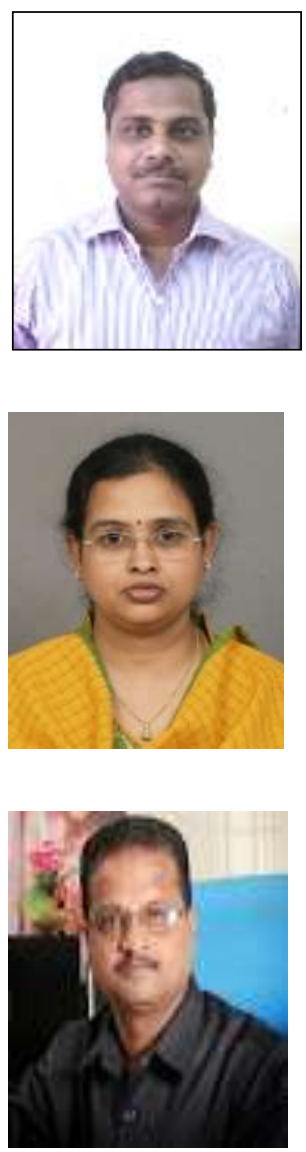

K.Venkataramanan was born in 1975 in Panruti. He has obtained B.E (Electrical and Electronics) and M.E (Power Elecrtonics and Drives) degrees in 2002 and 2009 respectively from Annamlai University, Chidambaram, India and Anna University, Chennai, India. He has been working in the teaching field for about 11 years. His areas of interest include inverter, converter and drives. He has 8 publications in international journals. He has presented 10 technical papers in various national / international conferences. Currently, he is working as Assistant Professor in the Department of EEE, Arunai Engineering College, Tiruvannamalai, India. He is a life member of Indian Society for Technical Education. Contact number- +919443581125.

E-mail:raceramana@gmail.com.

B.Shanthi was born in 1970 in Chidambaram. She has obtained B.E (Electronics and Instrumentation) and M.Tech (Instrument Technology) from Annamalai University and Indian Institute of Science, Bangalore in 1991 and 1998 respectively. She obtained her Ph.D in Power Electronics from Annamalai University in 2009. She is presently a Professor in Central Instrumentation Service Laboratory of Annamalai University,Chidambaram,India. She has put in a total service of 21 years since 1992.Her research papers (11) have been presented in various / IEEE international /national conferences. She has 4 publications in national journal and 50 in international journals. Her areas of interest are: modeling, simulation and intelligent control for inverters. Contact number- +91- 9443185211.

Email: shancisl@gmail.com.

T.S.Sivakumaran was born in Panruti, India, on December 18, 1969. He has obtained B.E (Electrical and Electronics) and M.Tech (Power Electronics) in 1998 and 2002 respectively from Annamalai University and VIT University, Vellore and then Ph.D. in Power Electronics from Annamalai University, Chidambaram in 2009. He is currently Dean (PG studies) in Department of Electrical and Electronics Engineering, Arunai College of Engineering, Tiruvannamalai, India. His research papers (35) have been presented at IEEE International /national Conferences. He has two and ten publications in National and International journals. His area of interest are : converters, controllers and drives. He is a life member of Institution of Engineers (India), Indian Society for Technical Education and IEEE member. Contact number - +919443789987 Email:sivakumaran1969@gmail.com 